Acta bot. bras. 1(2):27-40 (1988) supl.

\title{
ASPECTOS DA EVOLUÇÃO E DA GEOGRAFIA DO GÊNERO PHILODENDRON SCHOTT (ARACEAE)
}

\begin{abstract}
RESUMO - O gênero Philodendron se divide em três subgêneros, cada um com distintos padrōes de morfologia, anatomia e distribuição. Em análise filogenética, o subgênero Meconostigma, o único com centro de especiação no sudeste do Brasil, mostra-se bastante apomórfico, ainda que cladisticamente primitivo no gênero. Análises fenéticas mostram que o gênero se constitue um taxon distinto, apesar de não ter um só caráter definitivo. Mostram também que feneticamente, Philodendron está mais perto de certos gêneros da África ocidental (Culcasia, Cercestis, Rhektophyllum) do que dos gêneros principalmente asiáticos com os quais está ligado pela classificação tradicional. A morfologia do gineceu varia muito no subgênero Meconostigma, com as formas mais simples ocorrendo no sudeste do Brasil e as mais elaboradas na Amazônia. Comparação com o "grupo de fora" indica que as formas mais simples são primitivas no subgênero, apontanto as espécies principalmente rupícolas, $P$. adamantinum Schott e $P$. leal-costae Mayo \& G.M.Barroso, como as de gineceus mais primitivos. Com base na morfologia do gineceu, poderia ser sugerido que o subgênero evoluiu em princípio na parte oriental do Brasil, como um grupo adaptado aos habitats abertos, e que na bacia amazônica ele chegou somente mais tarde. Os dois outros subgêneros, Philodendron e Pteromischum, surgiram posteriormente, principalmente como epífitas de florestas úmidas, e se mostram hoje mais diversos no nordeste da América do Sul.
\end{abstract}

\begin{abstract}
The genus Philodendron can be divided into three subgenera which are very distinct in vegetative and floral morphology, floral anatomy and distribution. Phylogenetic and phenetic analysis of floral characters indicate that subgenus Meconostigma, which unlike subgenera Philodendron and Pteromischum has a predominantly southeastern range in South America, is highly apomorphic but cladistically primitive in the genus. Phenetic analyses show that the genus can be viewed as distinct, although no definitive diagnostic character is known to exist. These analyses also show that Philodendron is phenetically closer to certain west African genera (Culcasia, Cercestis, Rhektophyllum) than to the mainly Asiatic genera with it has been traditionally associated. Gynoecial morphology in subgen. Meconostigma varies considerably, with simpler forms predominating in southeastern Brazil, and the most elaborate in Amazonia. Outgroup comparison suggests that the simpler types are more primitive and indicates that the rupicolous species $P$. adamantinum Schott and $P$. leal-costae Mayo \& G.M.Barroso possess the most primitive gynoecial type. Based on gynoecial morphology it is suggested that the subgenus evolved initially in eastern Brazil as a group adapted to open habitats, arriving only later in the Amazon basin. The other two subgenera, Philodendron and Pteromischum, arose later, as epiphytes of humid forestes and today are most diverse in the northeast of South America.
\end{abstract}

Key-words: Philodendron, Araceae, biogeography, phylogenetic systematics

\section{Introdução}

O gênero Philodendron Schott, bem conhecido dos paisagistas pelo grande número de espécies ornamentais, é o segundo maior da faminia Araceae, com cerca de 350 espécies hoje reconhecidas (Bunting 1986, Mayo 1986). Sua área de distribuição é essencialmente neotropical, atingindo seu limite meridional na regiảo do Rio de la Plata. As espécies são particularmente bem diversificadas nas matas ómidas tropicais, mas também ocorrem em brejos, sobre afloramentos rochosos e até em regiões semiáridas.

(1) Herbarium, Royal Botanic Gardens, Kew, Richmond, Surrey TW9 3AE, UK. 
Um conhecimento detalhado da geografia e da taxonomia do gênero é interessante aos fitogeógrafos devido ao grande número de espécies e a sua diversidade (veja por exemplo, os resultados de French \& Tomlinson 1984). Porém, os conhecimentos taxonómicos ao nível específico de que dispomos atualmente permanecem ainda superficiais. Novas espécies tem sido descobertas continuamente a taxas que não tem decrescido (Bunting 1975, 1986). Baseado èm dados existentes, o gênero pode ser dividido em três subgêneros, Philodendron, Pteromischum e Meconostigma, que são bem distintos em morfologia floral e vegetativa, anatomia floral e distribuição.

Um estudo taxonômico recente de Philodendron subgen. Meconostigma, o menor dos três subgêneros (Mayo 1986), forneceu novos dados com certos pontos de interesse ao fitogeógrafo, ainda que especulativos. O presente trabalho consta de um esboço dos resultados relevantes e do contexto taxonômico.

\section{Material e Métodos}

Na preparação da revisão de Philodendron subgen. Meconostigma, material herborizado dos seguintes herbários foi utilizado; A, B, C, CAY, CTES, E, F, G, HB, HBG, INPA, K, L, LE, M, MBM, MICH, MO, NY, P, RB, S, SEL, SPF, U, UB, UC, UEC, US. Para o estudo da morfologia e da anatomia floral do gênero, foi utilizado material vivo e preservado em álcool, colhido ou no campo no Brasil ou das coleções cultivadas do Roberto Burle Marx e do Royal Botanic Gardens, Kew.

A anatomia floral foi estudada ou através da dissecção de flores inteiras fixadas, utilizando um microscópio Olympus (modelo SZ-III, binocular), ou através de seções em série de flores impregnadas com a cêra "Paraplast", e cortadas com um microtômio do tipo Jung Model 1130. Todas as seçōes foram coloridas utilizando safranina 'O' e "alcian blue", e montadas em "euparal"; são todas depositadas nas coleções do Royal Botanic Gardens, Kew.

\section{Resultados e Discussão}

\section{Definição de Philodendron subgênero Meconostigma}

Este taxon sempre foi admitido pelos botânicos que estudaram o gênero, desde o reconhecimento do próprio gênero (Schott 1829). Os caráteres diagnósticos, de acordo com a tradição, incluem os seguintes: 1) hábito arborescente, 2) caule duro e fibroso coberto das cicatrizes de folhas velhas dispostas em espirais, e, 3) estames finos e compridos.

O subgênero Meconostigma é também distinto geograficamente, tendo sua maior diversidade nas regiōes sul e leste da região tropical da América do Sul. Na bacia amazônica o número de espécies é bem menor e, nas vertentes pacíficas dos Andes, na parte setentrional da Colombia e nas Antilhas, o subgênero é desconhecido (Figs. 1-16). Em contraste marcante, os subgêneros Philodendron e Pteromischum atingem sua maior diversidade na região noroeste da América do Sul, com espécies que alcançam o México e as Antilhas.

Meu estudo (Mayo 1986) confirmou que o subgênero tem limites bem definidos e ampliou o número de caracteres que o diferenciam dos dois outros subgêneros, Philodendron e Pteromischum. De acordo com os novos dados, o subgênero Meconostigma pode ser definido pelos seguintes caráteres:

I) Zona estéril do espádice (composta de estaminódios) longa, entre zonas pistiladas e estaminíferas.

II) Espata espessa. 
III) Caule adulto composto morfologicamente de unidades simpodiais de uma folha só, e de um padrão caracterizado pela supressão do internó hipopodial.

IV) Vascularização do gineceu mostrando um sistema axilar de feixes o qual é independente do sistema que fornece os óvulos através dos funículos.

V) Feixe vascular do estame não bifurcado.

VI) Dutos de resina na zona adaxial da espata tendo a forma de "J" em seção longitudinal.

2. Posição cladistica de Philodendron subgen. Meconostigma

A base das idéias filogenéticas apresentadas neste trabalho vem de um estudo anatômico dos caráteres da inflorescência em 15 espécies do gênero Philodendron, representando a maioria das seçōes atuais (Tabela 1). Das espécies estudadas, quatro pertencem ao subgênero Meconostigma e onze ao antigo subgênero "Euphilodendron" reconhecido por Krause (1913).

\section{TABELA 1}

Espécies do gênero Philodendron estudadas ao nível anatômico (para resultados completos veja Mayo 1986).

Subgênero Meconostigma

$P$. bipinnatifidum Schott ex Endlicher

$P$. goeldii G.M.Barroso

$P$. saxicolum K.Krause

$P$. williamsii J.D.Hooker

Subgênero Pteromischum

Subgênero Philodendron

Seção Baursia

$P$. insigne Schott

$P$. longilaminatum Schott

$P$. frits-wentii Bunting

Seção Calostigma

$P$. smithii Engler

P. burle-marxii G.M.Barroso

Seção Tritomophyllum

Seção Polytomium

$P$. tripartitum (Jacquin) Schott

Seção Schiz( ; $;$ hyllum

$P$.fendleri Engler

Seção Macrolonchium

P. pedatum (W.J.Hooker) G.Don

Seção desconhecida

P. melinonii Brongniart

$P$. "sp. nov. do Equador"

As Seções Philodendron e Camptogynium, ambas do subgênero Philodendron, não foram estudadas. 
Para a análise cladística das quinze espécies, utilizaram-se 41 caracteres anatômicos da inflorescência e, como "grupo de fora", a maioria dos gêneros tradicionalmente associados com Philodendron da subfamnia Philodendroideae (Engler 1912), junto com Cercestis, Rhektophyllum, Nephthytis e Montrichardia da subfamflia Lasioideae, e Culcasia da suḅfamnia Pothoideae (Mayo 1986). O cladograma resultante forneceu dados que reforçam o reconhecimento dos três subgêneros Meconostigma, Pteromischum e Philodendron.

$\mathrm{O}$ subgênero Meconostigma tem um número relativamente grande de caracteres autapomórficos e trata-se, portanto, de um taxon bem distinto. Porém, cladisticamente, o subgênero é o mais primitivo dos três, de acordo com esta análise. Os subgêneros Pteromischum e Philodendron são grupos-irmãos, e juntos formam o grupo-irmão do subgênero $M e$ conostigma (Fig. 17).

O cladograma é baseado exclusivamente em caracteres da anatomia floral, e assim pode ser testado por comparação com outros caráteres provávelmente derivados (apomórficos) destes subgêneros. A distribuição destes caráteres se mostra congruente com o cladograma. Assim, o subgênero Meconostigma, delimitado no cladograma por caráteres anatômicos, pode também ser caracterizado pela longa zona estéril do espádice. $\mathrm{O}$ subgênero Pteromischum é também caracterizado pela morfologia do caule (composto de unidades simpodiais de muitas folhas ou 'pleiófilas'), com os caráteres associados: - lâmina foliar simples e bainhas foliares compridas. O subgêneros Philodendron pode ser também caracterizado pela morfologia do caule, que é composto de unidades simpodiais de uma única folha, mas nas quais o internó hipopodial é sempre bem desenvolvido enquanto que o primeiro internó da unidade é suprimido.

Esses caráteres, quando associados aos do cladograma original, forneceram os elementos para uma classificação (Fig. 17) que permite supor a seguinte hipótese para a história do gênero. Do Philodendron ancestral, o subgênero Meconostigma foi o primeiro a surgir. O subgênero Pteromischum resultou de uma adaptação estreita ao hábito epiffítico na mata úmida, ligada à evolução de uma morfologia do caule muito espcializada. Muitos caracteres florais, porém, permaneceram plesiomórficos (generalizados) e parecidos aos dos gêneros do "grupo de fora".

Subgênero Philodenuron desenvolveu uma morfologia caulinar caracteristica e um sistema excepcional de dutos resiniferos no espádice. A secreção de resina na inflorescência durante ântese ocorre em quase todas as espécies estudadas, mas é excretada do espádice apenas em subgênero Philodendron (Mayo 1986). Subgênero Philodendron é o mais diversificado em número de espécies, abrangendo a maioria das espécies do próprio gênero.

\section{Morfologia do gineceu no subgênero Meconostigma}

O gineceu do subgênero Meconostigma mostra ampla variação na estrutura do estileteie e no número de lóculos do ovário. Esta variação estrutural do estilete parece ser resultante de crescimento diferencial em três zonas diferentes durante ontogênese: -

I) extensão dos lóbulos estilares.

II) extensão da região do estilete na qual correm os canais estilares.

III) estensão, ou rebrotação, do ápice primário floral e desenvolvimento do mesmo em cúpula central estilar.

Estes três tipos de crescimento, ocorrendo quase simultaneamente, resultam em diversas formas maduras (Figs. 18-29). A comparação com aqueles gêneros do "grupo de fora" que apresentam um ovário multilocular (Homalomena, Anubias, Zantedeschia), sugere 
que a ocorrência de crescimento-extensão em cada uma das regiōes trata-se de um caráter apomórfico (derivado). Duas espécies, $P$. adamantinum (Fig. 18) e P. leal-costae (Fig. 19), se assemelham muito morfologicamente dos gêneros do "grupo de fora".

O número de lóculos do ovário, de 3 até 47 lóculos em cada ovário, é também muito variável. A comparação com os gêneros estudados no "grupo de fora" indica que ovários 3-loculados e 4-loculados são provavelmente plesiomórficos no gênero Philodendron, e 7 espécies mostram estas condições em pelo menos alguns dos gineceus num só espádice ( $P$. dardanianum (Fig. 20), $P$. brasiliense (não ilustrada), $P$. tweedianum (Fig. 21), $P$. uliginosum (Fig. 22), P. adamantinum (Fig. 18), P. corcovadense (Fig. 24), P. leal-costae (Fig. 19) ).

4. A relação entre geografia, hábitos e morfologia do gineceu no subgênero Meconostigma

A ecologia das espécies sugere que o subgênero Meconostigma é bem adaptado a ambientes abertos com alto grau de insolação. Porém, no ambiente florestal este subgênero tem sido relativamente menos bem sucedido.

Todas as espécies com gineceu exibindo número elevado de caracteres plesiomórficos ocorrem no leste e no sul da área de distribuição do subgênero (Grupo A, Tabela 2, Figs. $3,6-8,10-11,14,16)$ e mostram mais variação ecológica ainda que todas sejam de ambientes abertos. São, portanto, plantas aquáticas, saxícolas, epifíticas ou terrestres sobre substrato arenoso, como, por exemplo, a restinga. As duas espécies com a morfologia mais primitiva, $P$. leal-costae (Fig. 3) e $P$. adamantinum (Fig. 6), são saxícolas, ainda que $P$. leal-costae ocorra também em restingas no estado de Alagoas (Fonseca-Vaz et al. 1984).

Em contraste, as três espécies que ocorrem na região amazônica, $P$. goeldii, $P$. venezuelense e $P$. solimoesense (Grupo C, Tabela 2, Figs. 1-2, 4) têm gineceus mais derivados, com estiletes muito elaborados e geralmente mais de 20 lóculos em cada ovário. São todas espécies epifíticas em mata fechada e plantas terrestres em ambientes mais abertos.

Outras espécies com morfologia estilar apomórfica ocorrem no leste e no sul da área de distribuição (Grupo B, Tabela 2, Figs. 5, 9, 12-13, 14) e mostram variação de hábito parecida com a das espécies do Grupo A, com plantas aquáticas ( $P$. brasiliense, Fig. 12; $P$. undulatum, Fig. 13), saxícolas ( $P$. saxicolum, Fig. 5), e epifíticas ( $P$. williamsii, Fig. 9). As diversas formas de $P$. bipinnatifidum (Fig. 14), que têm gineceus de caráter apomórfico, se enquadram neste grupo de espécies.

\section{Padrōes históricos e geogrǻficos do subgênero Meconostigma}

Na bacia amazônica, a ocorrência de poucas espécies de hábito mais uniforme e com morfologia do gineceu muito derivada sugere que o subgênero Meconostigma poderia ter colonizado essa regiăo numa época relativamente recente em contraste com a parte sudeste da área de distribuição, onde as espécies são mais numerosas, mais diversificadas em hábito e mostram, pelo menos em alguns casos, morfologia do gineceu primitiva.

Por outro lado, pode ser suposto que nas condiçōes climáticas atuais, a bacia amazônica oferece um conjunto de ambientes ecológicos muito mais restrito a esse grupo de plantas heliófilas, e que apenas umas poucas espécies especializadas sobreviveram á ampliação da área de floresta úmida desde o Pleistoceno, quando o clima daquela região era mais árido, e talvez mais favorável ao florescimento de um número maior de espécies.

Porém, é evidente que as matas da regiảo atlântica oriental do Brasil têm espécies que săo epifíticas mas tambe̊m mostram gineceus generalizados e que, dentro da regiāo amazônica, há um grande conjunto de áreas de habitat mais aberto, como por exemplo as serras guianenses e imensas áreas brejosas, onde espécies análogas às do Brasil oriental poderiam prosperar, mas nunca foram descobertas. 


\section{TABELA 2}

Philodendron subgênero Meconostigma - Hábito em relação a morfologia do gineceu

Espécie

Hábito

A. Espécies do sudeste com gineceu relativamente primitivo
$P$. adamantinum
saxicola
$P$. leal-costae
saxicola, terrestre
$P$. dardanianum
aquática
$P$. tweedianum
aquática
$P$. uliginosum
aquática
P. speciosum
epifita, saxícola
$P$. corcovadense
epifita, terrestre
$P$. bipinnatifidum*
aquática, saxicola, epf́fita

B. Espécies do sudeste com gineceu mais especializado
P. brasiliense
aquática
$P$. undulatum
aquática
$P$. saxicolum
saxicola
P. williamsï
epffita, terrestre
$P$. bipinnatifidum *
aquática, saxicola, epffita

C. Espécies amazônicas com gineceu muito derivado
$P$. goeldii
epffita, terrestre
$P$. venezuelense
epffita, terrestre
$P$. solimoesense
epfitita, terrestre

* P. bipinnatifidum é muito variável em morfologia floral e vegetativa (veja Mayo 1986).

Além disso, a distribuição das espécies amazônicas é muito mais extensa do que a da maioria das espécies orientais, entre as quais há exemplos de espécies estreitamente endêmicas ( $P$. adamantinum, $P$. saxicolum, $P$. speciosum). Estes fatos sugerem que tais espécies orientais sejam muito antigas, enquanto que as espécies amazônicas são de origem mais recente.

\section{Evolução e geografia do gênero Philodendron}

As duas hipóteses referentes ao subgênero Meconostigma, uma posição cladística primitiva e uma área de distribuiç̧ão relictual no Brasil oriental, dấo apoio à possibilidade de que o grupo irmăo do gênero consta dos três gêneros africano-ocidentais Cercestis, Rhektophyllum e Culcasia. Os estudos de French (com. pess.) e French \& Tomlinson (1984) já indicaram que esses quatro gêneros sảo bem mais próximos do que antes pensavam os taxonomistas. A evolução do conjunto de gêneros deve ter ocorrído na superfície da Gondwana-oriental, e o subgênero Meconostigma poderia ter aparecido no princípio da história do coñtinente da América do Sul oriental, talvez então se desenvolvendo como um grupo de espécies adaptadas a ambientes abertos.

Entre as espécies dos subgêneros Pteromischum e Philodendron; porém, a maioria são epf́fitas e poucas são adaptadas a situações expostas. Epifitas destes subgêneros são típicas de ambientes sombreados abaixo da copa da floresta, sobre troncos ou galhos maiores. Estes dois subgêneros devem ter evoluido essencialmente como plantas de floresta úmida, particularmente no caso do subgênero Pteromischum. 
As áreas de distribuição dos subgêneros Pteromischum e Philodendron sugerem: uma história condicionada principalmente pela alteração continua do mosaico de áreas de florestas úmida inferidas pelo modelo dos "refúgios" (Prance 1982). Os centros principais de diversidade específica correspondem, pelo menos parcialmente, a alguns dos refúgios indicados para a América do Sul. Possivelmente como reação ao desenvolvimento de retúgios florestais, bem como à diversificação ecológica provocada pela orogenia dos Andes, o slibgênero Philodendron passou por um processo intenso de especiação, especialmente no Peru, Equador, Colombia, Panamá e Venezuela.

\section{Relaçōes taxonômicas do gênero Philodendron}

Engler (1912) ligou Philodendron com dois gêneros principalmente asiáticos, Homalomena e Schismatoglottis, e esse conceito foi mantido por Borger e Nicolson (1987). O estudo de Grayum (1984) sobre as afinidades genéricas resultou em conclusões bastante diferentes. Ele sugere que Philodendron é mais próximo a Dieffenbachia, um gênero neotropical.

Uma análise fenética de 14 gêneros (Figs. 30-31), utilizando 40 caracteres principalmente da inflorescência (veja Mayo 1986 para uma apresentação mais detalhada), mostrou que: -

I) os três subgêneros de Philodendron agrupam-se mais entre si do que a qualquer outro gênero (Fig. 31);

II) o gênero feneticamente mais prôximo a Philodendron é Cercestis, da África oriental.

A análise mostrou também que Philodendron é sistemáticamente bastante isolado e que não tem relação estreita com nenhum gênero analisado (Fig. 30-31). Esta conclusão, ainda que inconclusiva, indica que não há argumento firme para manter a ligação tradicional do gênero com Homalomena e Schismatoglottis, mas ao mesmo tempo, apoia a hipótese, já discutida, de o grupo Cercestis-Rhektophỵllum-Culcasia é seu "grupo-irmão".

\section{Geografia dos gêneros da subtamíla $P$ hulodendroidecıe}

A proposta relação africana de Philodenciron tem poucas semelhanças na familia das Araceae de acôrdo com idéias atuais da taxonomia. Mayo (1987) e Grayum (1984) discutem as ligações transatlânticas da família, das quais as mais bem definidas parecem ser uma entre Callopsis (África oriental) e Uleurum (região amazônica do Peru), e outra entre Typhonodorum (Madagascar) e Peltundra (região oriental dos EUA).

Uma classificação melhor fundamentada é necessária antes de que uma análise rigorosa da biogeografia dos gêneros da subfamília seja possível. Uma análise cladística abrangendo todos os gêneros é o primeiro requisito. Apesar disso, dos dados disponíveis pode ser lançada a hipótese que o grupo-irmão de Philodendron é provavelmente o conjunto de Cercestis-Rhektophyllum-Culcusia, e que o taxon ancestral imediato deles ocorria na área continental hoje representada pela África ocidental e a parte oriental da América do Sul. Esta última região seria a área de distribuição inicial do gênero Philodendron, e a extensão setentrional do gênero até a América Central e México é considerada como uma ocorrência mais recente. 


\section{Agradecimentos}

Agradeço a Diretoria do XXXVIil Congresso Nacional de Botânica, realizado na Universidade de São Paulo, em janeiro 1987, e especialmente a Presidente, Nanuza Luíza de Menezes e a Primeira Secretária, Ana Maria Giulietti, pela oportunidade de participar do Congresso, por muita amizade e colaboração. Agradeço também ao Professor Vernon $\mathrm{H}$. Heywood, a quem devo apoio essencial durante a realização do estudo em que foi baseado o presente trabalho; ao Roberto Burle Marx por ter me permitido estudar a sua coleção maravilhosa de Aráceas; aos assessores pela revisão do português; e aos curadores dos seguintes herbários por ter me fornecido material: $A, B, C, C A Y, C T E S, E, F, G$, HB, HBG, INPA, L, LE, M, MBM, MICH, MO, NY, P, RB, S, SEL, SPF, U, UB, UC, UEC, US.

\section{Referências Bibliográficas}

BOGNER, J. \& NICOLSON D.H. 1987. A revised classification of Araceae with dichotomous keys. In J.Arditti \& L.Nyman, The Biology of the Araceae (no prelo).

BUNTING, G.S. 1975. Nuevas especies para la revision de las Araceas venezolanas. Acta Bot. Venezuel. 10: $263-335$.

BUNTING, G.S. 1986. New taxa of Venezuelan Araceae. Phytologia 60(5): 293-344.

ENGLER, A. 1912. Araceae-Philodendroideae-Philodendreae. Allgemeiner Teil, Homolameninae und Schismatoglottidinae. Em A. Engler (ed.), Das Pflanzenreich 55 (IV. 23Da): 1-134.

FONSÊCA-VAZ, A.M.S., Andreata R.H.P. \& Guedes P.R. 1984. Philodendron leal-costae Mayo \& G.M.Barroso (Araceae) - Observaçōes sôbre sua distribuição geográfica, morfologia e ecologia. Anais XXXIV Congr.Nac.Bot., Porto Alegre, Brasil 2: 229-233.

FRENCH, J.C.\& TOMLINSON P.B. 1984. Patterns of stem vasculature in Philodendron. Amer. J.Bot. 71: $1432-1443$.

GRA YUM, M.H. 1984. Palynology and Phylogeny of the Araceae. Ph. D dissertation, Univ. Massachusetts (Amherst), EUA.

KRAUSE, K. 1913. Araceae-Philodendroideae-Philodendreae-Philodendrinae. In A. Engler (ed.), Das Pflanzenreich 60 (IV.23Db): 1-143.

MAYO, S.J. 1986. Systematics of Philodendron Achott (Araceae) with special reference to inflorescence characters, Ph.D. thesis, University of Reading, UK.

MAYO, S.J. 1987. Aspects of Aroid Geography (manuscrito).

PRANCE, G.T. 1982 (ed.). Biological Diversification in the Tropics. Columbia Univ. Press, New York.

SCHOTT, H.W. 1829. Für Liebhaber der Botanik. Wiener Zietschr. Kunst, Literatur, Theater und Mode 1829 (Drittes Viertel) 94:.779-780. 


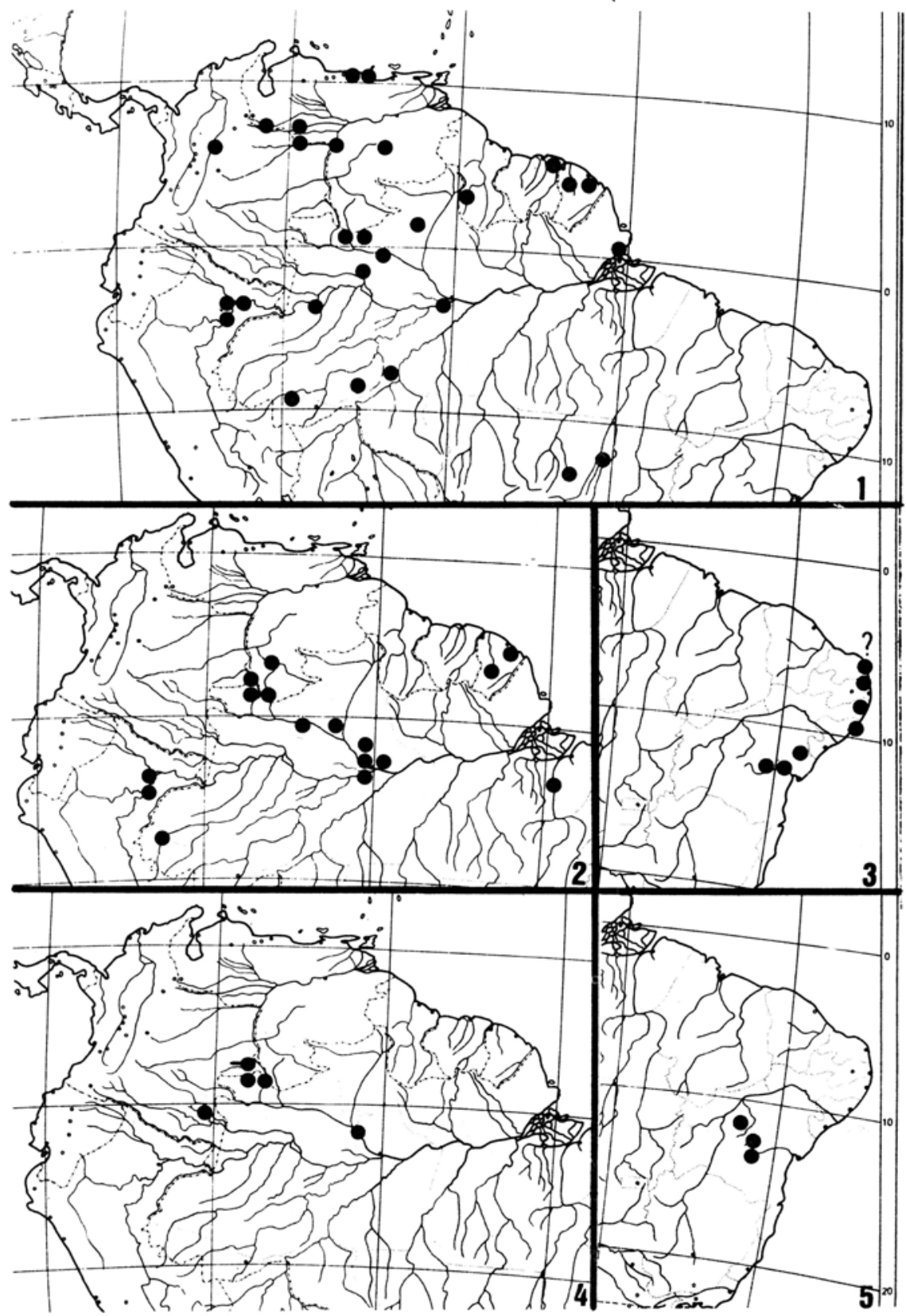

FIGURAS 1-5

Àreas de distribuição em Philodendron subgen. Meconostigma.

Fig. 1. P. solimoesense A.C.Smith; Fig. 2. P. goeldii G.M.Barroso; Fig. 3. P. leal-costae Mayo \& G.M.Barroso; Fig. 4. P. venezuelense Bunting; Fig. 5. P. saxicolum K. Krause; 


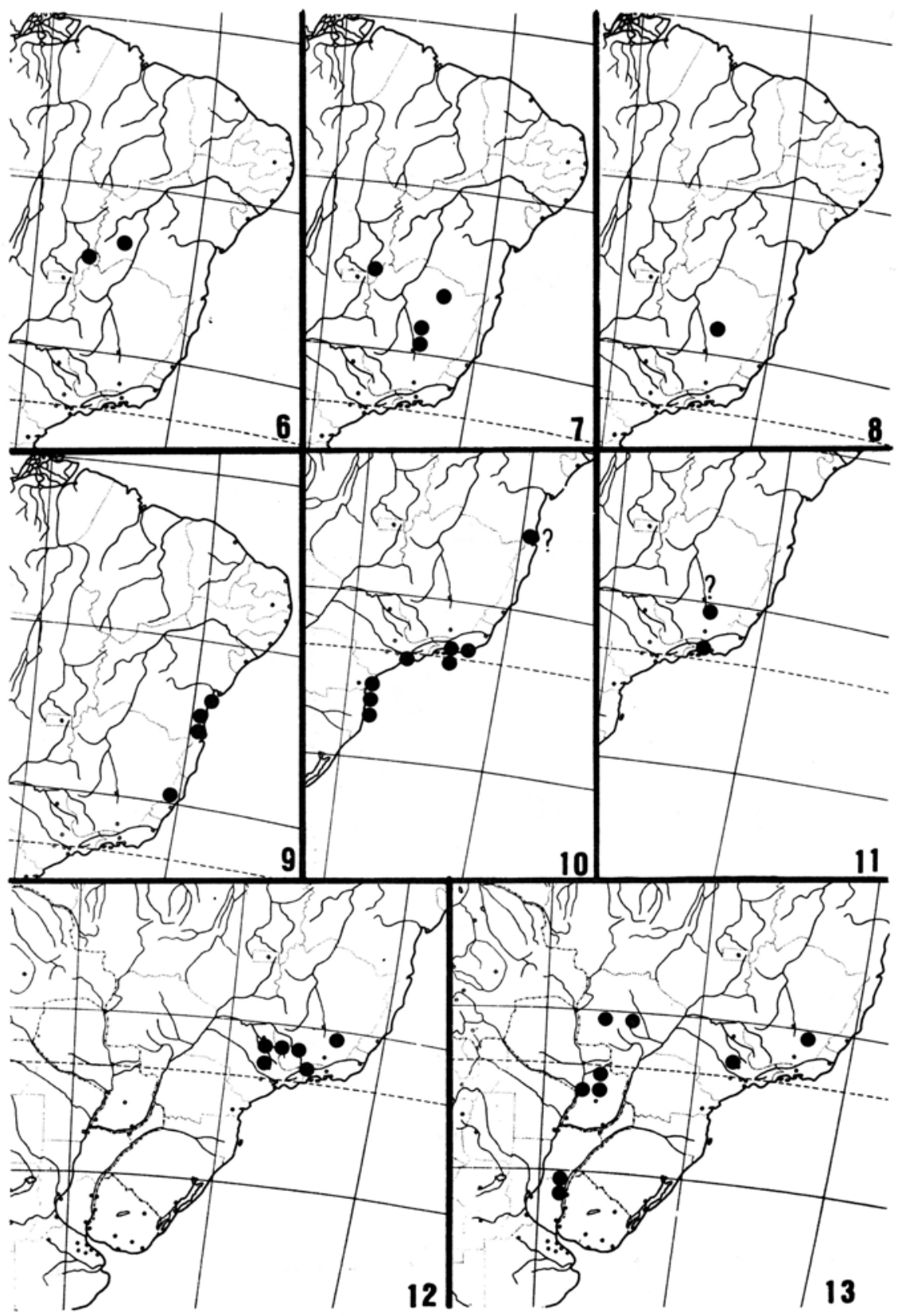

\section{FIGURAS 6-13}

Àreas de distribuiçăo em Philodendron subgen. Meconostigma.

Fig. 6. P. dardanianum Mayo, sp. ined; Fig. 7. P. uliginosum Mayo, sp. ined; Fig. 8. P. adamantinum Schott, Fig. 9. P. williamsii J.D. Hooker, Fig. 10. P. corcovadense Kunth; Fig. 11. P. speciosum Schott ex Endlicher, Fig. 12. P. brasiliense Engler, Fig. 13. P. undulatum Engler 


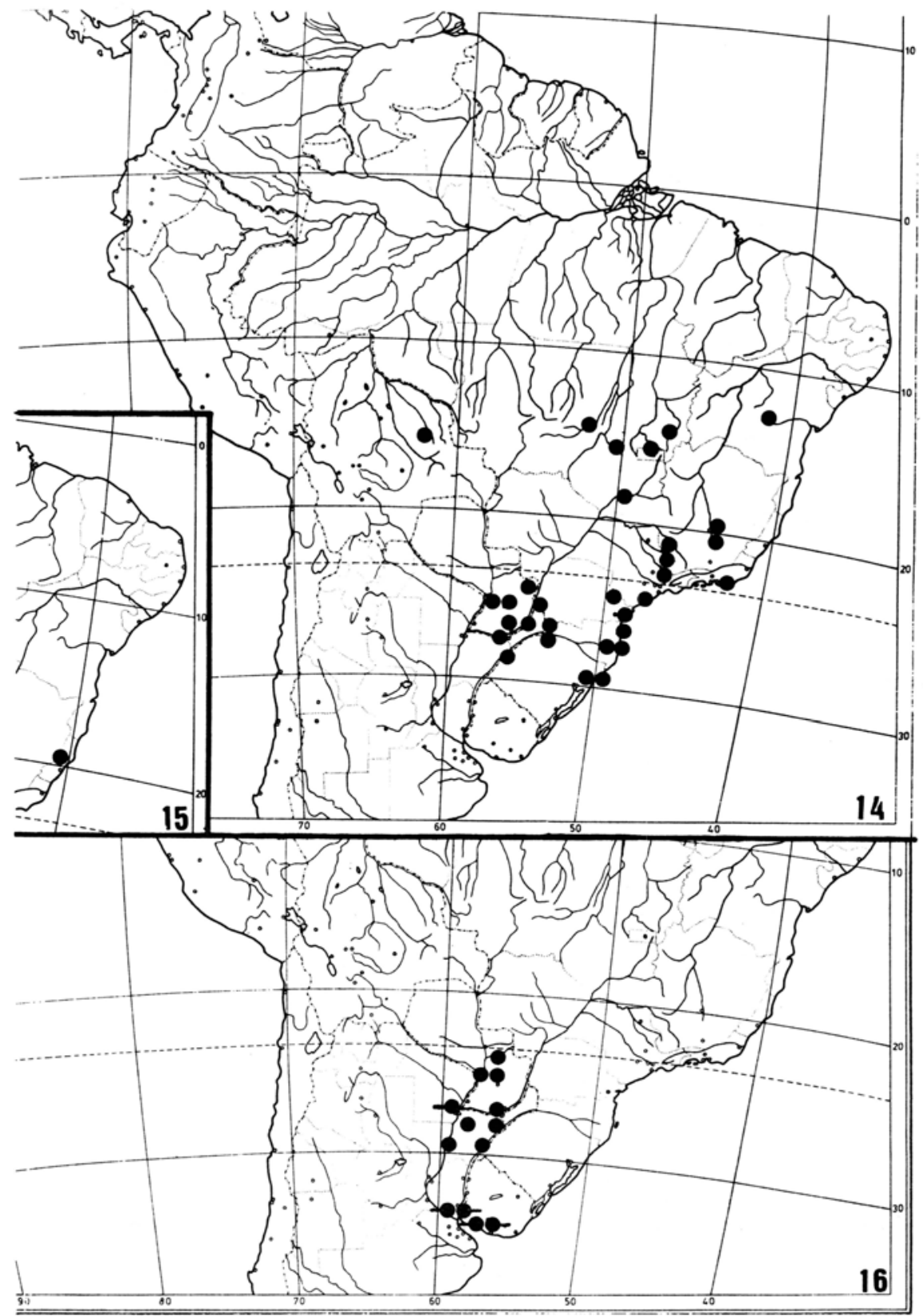

FIGURAS 14-16

Àreas de distribuição em Philodendron subgen. Meconostigma.

Fig. 14. P. bipinnatifidum Schott ex Endlicher; Fig. 15. P.sp. A; Fig. 16. P. tweedianum Schott 


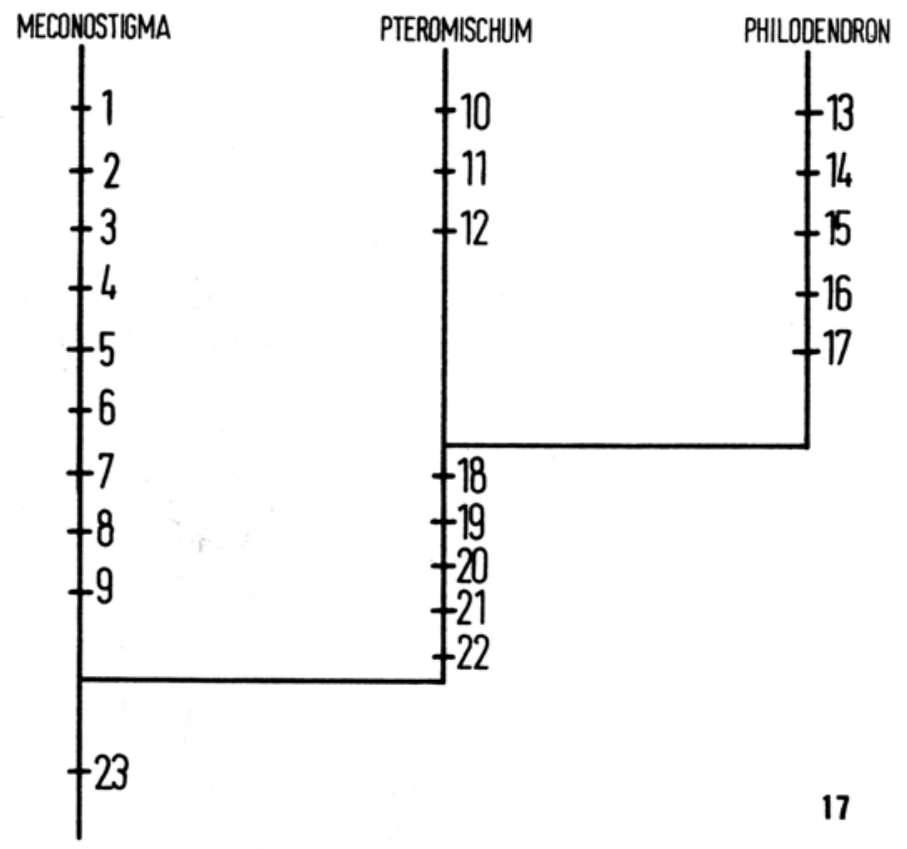

FIGURA. 17

Classificação dos três subgêneros de Philodendron (a sigla * indica um caráter apomórfico)

\section{Caracteres}

1. Centro de diversificaçăo especffica no sudeste do Brasil

2. "Canais estilares independentes no gineceu

3. "Zona estéril do espádice longo.

4. "Sistema vascular do gineceu com feixes axilares independentes

5. "Estames finos e compridos

6. "Feixe vascular do estame não bifurcado

7. "Dutos de resina da zona adaxial da espata com forma de "J"

8. "Espata muito espessa

9. "Internódio hipopodial da unidade simpodial do caule suprimido

10. *Tanino faltando no estame e no gineceu

11. "Ráfides periféricas no estilete

12. "Unidades simpodiais do caule com muitas folhas ("pleiofilas")

13. *Sulcos estômiais do estame ausentes

14. "Tecas do estame contíguas

15. "Resina excretada no espádice

16. *Plexo vascular do estilete faltando

17. *Primeiro internódio da unidade simpodial do caule suprimido

18. Centro de diversificação especffica no noroeste da América do Sul

19. *Lóbulos estilares faltando

20. "Tanino faltando na epiderme do estame

21. *Constrição central da espata bem evidente

22. "Canais estilares independentes no gineceu

23. Grupo justificado por similaridade fenética em comparaçăo com os gêneros do "grupo de fora" (Cercestis, Rhektophyllum, Culcasia, Nephthytis, Aglaonema, Zantedeschia, Anubias, Homalomena, Schismatoglottis, Montrichardia, Peltandra, Typhonodorum, Dieffenbachia, compare com Fig. 3) 

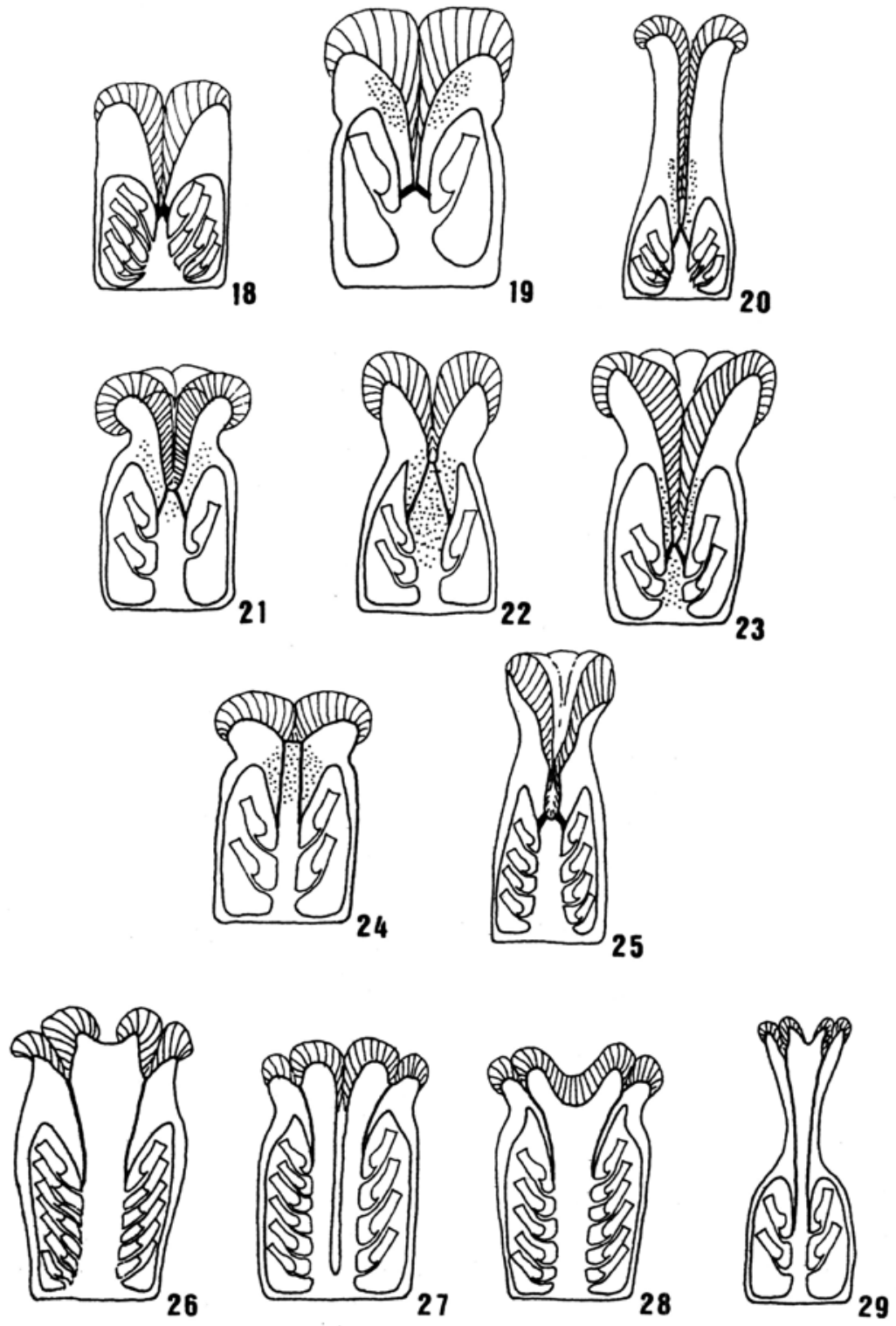

\section{FIGURAS 18-29}

Morfologia do gineceu em espécies de Philodendron subgênero Meconostigma, em seção longitudinal. Linhas obliquas indicam tecido do estigma; áreas pontilhadas indicam a presença de ráfides; linhas espessas indicam a posição dos canais estilares independentes.

18. P. adamantinum Schott; 19. P. leal-costae Mayo \& G.M.Barroso; 20. P. dardanianum Mayo, sp. ined.; 21. $P$. tweedianum Schott, 22. P. uliginosum Mayo, sp. ined.; 23. P. speciosum Schott ex Endlicher, 24. $P$. corcovadense Kunth; 25. P. bipinnatifidum Schott ex Endlicher; 26. P. goeldii G.M.Barroso; 27-28. P. solimoesense A.C.Smith; 29. P. venezuelense Bunting. 

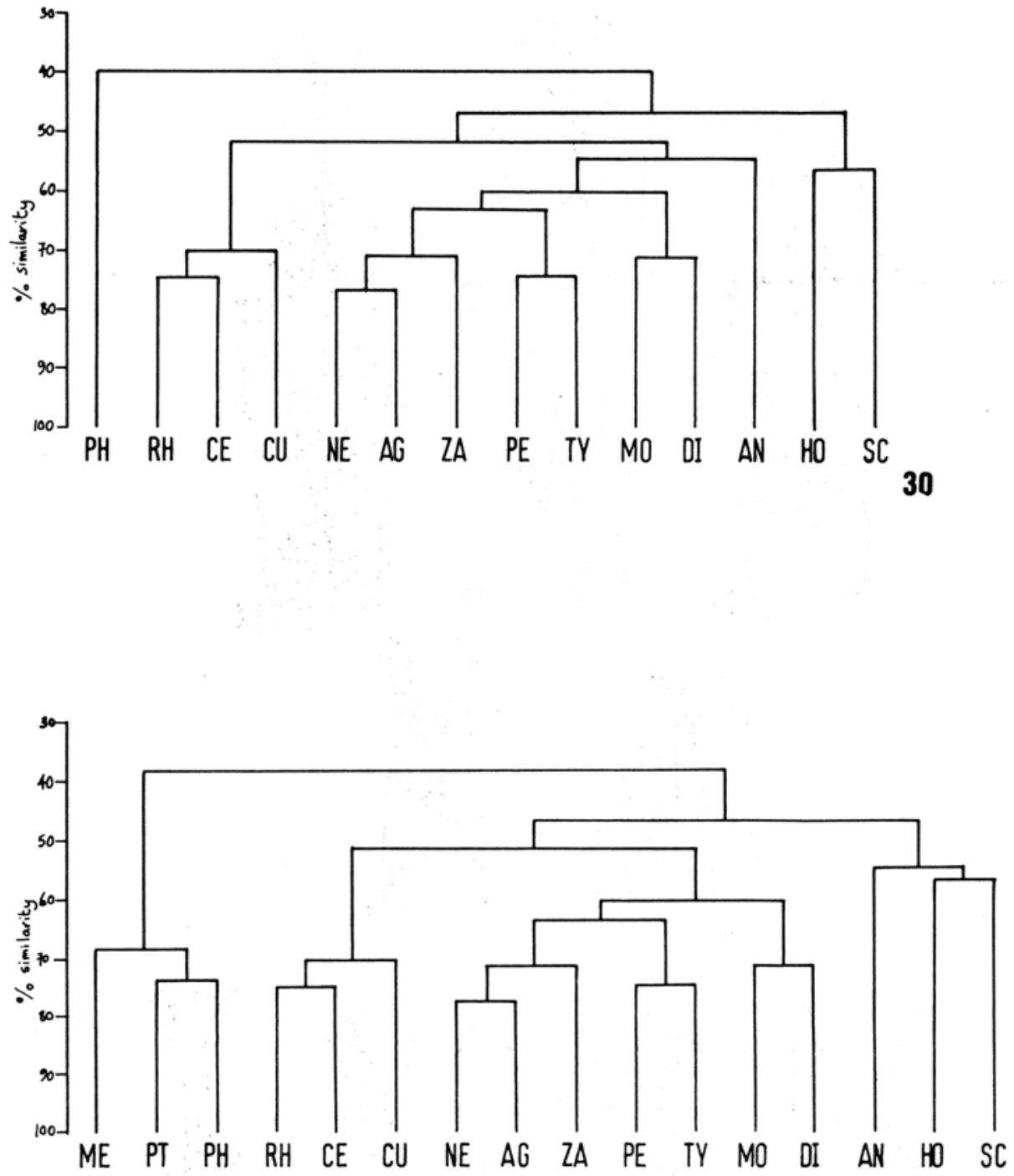

\section{FIGURAS 30-31}

Fenogramas dos gêneros da subfamília Philodendroideae, resultantes de uma análise tipo "Average Linkage Cluster Analysis", utilizando o programa chamado "GENSTAT".

30. Matriz 1 - Philodendron tratado como um só gênero.

31. Matriz 2 - Cada subgênero de Philodendron tratado independentemente.

AG - Aglaonema; AN - Anubias; CE - Cercestis; CU - Culcasia; DI - Dieffenbachia; HO - Homalomena; ME - Philodendron subgen. Meconostigma; MO - Montrichardia; NE - Nephthytis; PE - Peltandra; PH - o gênero Philodendron (Fig. 30); PH - Philodendron subgen. Philodendron (Fig. 31); PT - Philodendron subgen. Pteromischum; RH - Rhektophyllum; SC - Schismatoglottis; TY - Typhonodorum; ZA - Zantedeschia. 